\title{
Charting the Maze
}

It may be good, like it who list, But I do doubt. Who can me blame?

Alas, I tread an endless maze That seek to accord two contraries; And hope still, and nothing haze, Imprisoned in liberties. . . .

— Sir Thomas Wyatt, Ballade 85

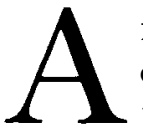

NCIENT and medieval labyrinths or mazes (the words have different etymologies but mean the same thing) are characteristically double. They are full of ambiguity, their circuitous design prescribes a constant doubling back, and they fall into two distinct but related structural categories. They presume a double perspective: maze-treaders, whose vision ahead and behind is severely constricted and fragmented, suffer confusion, whereas maze-viewers who see the pattern whole, from above or in a diagram, are dazzled by its complex artistry. What you see depends on where you stand, and thus, at one and the same time, labyrinths are single (there is one physical structure) and double: they simultaneously incorporate order and disorder, clarity and confusion, unity and multiplicity, artistry and chaos. They may be perceived as path (a linear but circuitous passage to a goal) or as pattern (a complete symmetrical design). They are dynamic from a maze-walker's perspective and static from a privileged onlooker's point of view. Their paths are linear, but-since many ancient and medieval labyrinths are round-their pattern may be circular, cyclical; they describe both the linearity and the architecture of space and time. They may be inextricable (if no one can find the exit) or impenetrable (if no one can find the center). Our perception of labyrinths is thus intrinsically unstable: change your perspective and the labyrinth seems to change. As images, then, labyrinths are convertible and relative: what you see and feel and understand one moment can shift completely the 
next like a reversible figure, an optical illusion. Thus mazes encode the very principle of doubleness, contrariety, paradox, concordia discors, as Wyatt knew. ${ }^{1}$

Accordingly, the aims of this book are dual: to reconstruct the idea of the labyrinth in the western Middle Ages by extrapolation from a wide variety of sources, both literary and visual, and to see how that idea informs an array of important literary texts. I use the word idea to mean the general governing concept of the labyrinth as a visual or verbal sign, its ruling principles, the theoretical set of characteristics abstracted from and manifested in the specific labyrinths of art or literature. The idea of the labyrinth thus encompasses both formal principles (e.g., circuitousness, complexity) and habitual, culturally shared and transmitted significances of labyrinths (e.g., artistry, imprisonment). Unlike a Platonic idea, the kind of idea I'm talking about is not "true," universal, or immutable; like other human ideas, the idea of the labyrinth is subject to temporal change, the most marked change occurring in postmedieval times, when the presence of false turnings and repeated choice became the labyrinth's dominant characteristic. But because there is considerable constancy in the idea of the labyrinth over many centuries, including those spanned by this book, I speak of an idea (albeit one with permissible variations), not of many ideas. Since it allows for certain variations, this idea is not monolithic, a fixed and perfect template; rather, it includes a small repertory of attributes and associations among which a mazemaker can select, emphasizing these as opposed to those to shape the precise significance of this particular maze, which will in turn be interpreted by readers or viewers in accordance with their familiarity with the received idea of the labyrinth.

The word idea is also appropriate because I am interested not only in "real" labyrinths-mazes one can see and touch, things that are labeled labyrinths - but also in metaphorical labyrinths and in the very concept of the labyrinth. Thus I am also concerned with the labyrinthine: with identifying certain features closely associated with labyrinths (for instance, enforced circuitousness; disorientation; the idea of planned chaos; ${ }^{2}$ the bivium or critical choice between two paths; inextricability; intricacy; complexity), and with examining how constellations of these features operate in things, metaphors, and texts that function like labyrinths even though they may not be identified as such. In this context, I have coined the term "labyrinthicity," by which I mean the condition of possessing significant features habitually associated with labyrinths.

1. See epigraph to this chapter and Ballade 85 in Sir Thomas Wyatt: The Complete Poems, ed. R. A. Rebholz (New Haven: Yale University Press, 1978), pp. 120-121.

2. I first encountered this phrase in Alfred David's "Literary Satire in The House of Fame," PMLA , 75 (1960), 333-339, where it struck me as the perfect definition of a maze. 
I speak of reconstructing the medieval idea of the labyrinth because I want to avoid imposing modern definitions and canons of interpretation on medieval mazes. The modern idea of a labyrinth is curiously limited. It holds that mazes must contain many points of choice between two or more paths (they are multicursal, to use a word that will recur throughout this study - see plate 4) with dead ends leading nowhere, and that they are intended to confuse and frustrate. This idea is not foreign to the Middle Ages: many literary texts assume a multicursal model, and some see confusion as the maze's primary function where others present bewilderment as merely a byproduct of brilliantly complex structure. But the modern concept of the maze excludes virtually all medieval labyrinths in the visual arts, which show a single winding path leading inevitably to the center and then back out again (they are thus unicursal-see plate 5). The medieval idea of the labyrinth allows both patterns, so modern readers must discard their mental image of the maze if they are to approach medieval examples and see what is actually there. Previous studies of medieval labyrinths have been seriously handicapped by their failure to appreciate, let alone to examine carefully, the implications of the coexistence of these radically different paradigms of the maze. Similarly, most modern studies of labyrinths manif est an interest in determining anthropological origins or archetypal significance. ${ }^{3}$ This search for the Ur-labyrinth may tell us something about twentieth-century ways of thinking about signs in general and the labyrinth in particular, and it can provide cross-cultural insights and suggestive speculation about the maze's prehistory, but it tells us next to nothing about how medieval people saw and used the sign and hence has no place in my discussion. Instead, I want to recover what medieval people actually thought about mazes, what their "horizon of expectations" might have been when they heard the word laborintus or saw a maze in a cathedral nave, what they meant by the sign in their own works; I want to describe an appropriate code for deciphering medieval visual or literary works involving literal or metaphorical labyrinths, to define the "literary competence" required

3. See, e.g., Janet Bord, Mazes and Labyrinths of the World (London: Latimer New Dimensions, 1976); Philippe Borgeaud, "The Open Entrance to the Closed Palace of the King: The Greek Labyrinth in Context," History of Religions, 14 (1974), 1-27; Gaetano Cipolla, Labyrinth: Studies on an Archetype (New York: Legas, 1987); Raymond J. Clark, Catabasis: Vergil and the Wisdom-Tradition (Amsterdam: B. R. Grüner, 1979); C. N. Deedes, "The Labyrinth," in S. H. Hooke, ed., The Labyrinth: Further Studies in the Relation of Myth and Ritual in the Ancient World (London: SPCK, 1935), pp. 3-42; Kern, Labirinti; W. F. Jackson Knight, Cumaean Gates: A Relation of the Sixth Aeneid to the Initiation Pattern (Oxford: Blackwell, 1936); Matthews, Mazes and Labyrinths; Jill Purce, The Mystic Spiral: Journey of the Soul (London: Thames \& Hudson, 1974); and Santarcangeli, Livre des Labyrinthes. My short study "The Labyrinth in Medieval Culture: Explorations of an Image," University of Ottawa Quarterly, $5^{2}$ (1982), 207-218, based on papers given at Oxford in 1975 and at Ottawa in 1981 , is very sketchy in comparison to the present book. 
to appreciate labyrinth references and intertextualities. ${ }^{4}$ The kinds of questions I want to answer are these: What was the documentable medieval reception and development of the form, concept, and meaning of the labyrinth, as witnessed by the broadest possible range of texts and visual images from both official and unofficial cultures? What were characteristic and atypical medieval ways of seeing the labyrinth? How did the idea of the labyrinth, both literary and visual, generate metaphor, and what are the consequent metaphorical uses of the sign ${ }^{5}$ How does the idea of the labyrinth function as a heuristic tool for understanding labyrinthine literary texts that may or may not explicitly identify themselves as labyrinths? This general focus on the medieval, the metaphorical, and the literary distinguishes my work from most recent studies of labyrinths.

Readers familiar with W. H. Matthews's seminal Mazes and Labyrinths, Paolo Santarcangeli's Livre des labyrinthes, and Hermann Kern's Labirinti may wonder why another book is necessary. First, these previous studies concentrate on the visual arts, not on literature, and certainly not on labyrinthine texts. Second, they treat the labyrinth from prehistory to the present, and the medieval idea of the labyrinth merits far more attention than they have given it. Third, despite their visual orientation, they give little or no attention to the formal implications of the two medieval paradigms of the maze and the tensions between literary and visual traditions. Fourth, my work deals more with metaphorical labyrinths than with real ones. ${ }^{6}$

The best way to suggest the scope, rationale, and methods of this book is through a brief overview of its contents. Part One lays the groundwork for the study of medieval labyrinths by examining several facets of the classical and early Christian background. Focusing on the written witness, Chapter 1 identifies, analyzes, and compares two major classical traditions associated with different kinds of literature and well-known to

4. See Hans Robert Jauss, "Literary History as a Challenge to Literary Theory," pp. 3-45 in Toward an Aesthetic of Reception, trans. Timothy Bahti, introd. Paul de Man (Minneapolis: University of Minnesota Press, 1982), and Jonathan Culler, "Literary Competence," pp. 101-117 in Reader-Response Criticism: From Formalism to Post-Structuralism, ed. Jane P. Tompkins (Baltimore: Johns Hopkins University Press, 1980). Culler's essay is excerpted from his Structuralist Poetics (Ithaca: Cornell University Press, 1975).

5. We encounter a chicken-or-egg question in regard to whether the visual image of the labyrinth generated myth and metaphor or vice versa. Given the great antiquity of the typical round, unicursal design, the visual image may have come first, begetting (or attaching to itself) myth and metaphor, but the question is really unanswerable.

6. I remain deeply in debted to Matthews's pioneering work and appreciative of the valuable studies of Santarcangeli, Kern, and Batschelet-Massini; these works have not significantly influenced my own approach or conclusions, but they have made this book shorter than I expected when I began my research in 1970 , for they cover some ground so ably that, to paraphrase a medieval commonplace, if in some ways I can see farther and more accurately, it is because I am standing on the shoulders of giants I can cite in footnotes. 
the Middle Ages-the historical-geographical, quasi-factual description of four ancient labyrinths as real buildings, discussed by Pliny the Elder, Strabo, and others, and the purely literary tradition established by Virgil and Ovid, the classical poets who most influenced medieval thought. Here I explore characteristically labyrinthine dualities-artistry vs. chaos, order vs. confusion, admirable complexity vs. moral duplicity-in these traditions and texts; I discuss the physical facts and narrative implications of the labyrinth and its associated myth; and I show how the written tradition presupposes the multicursal model of the maze, transmitting that model to the Middle Ages.

Chapter 2 focuses on the surprising conflict between written tradition and the visual arts, which endorse not the multicursal model but rather the unicursal model that persists in art throughout the Middle Ages. It is almost impossible to overestimate how remarkable this paradigmatic incompatibility is: as an analogy, imagine that literary descriptions of circles defined them as having four sides joined by right angles, whereas visual illustrations showed the figure we recognize as a circle. Other studies of the labyrinth at best mention the extraordinary discrepancy between medieval unicursal and modern multicursal visual models. But I will argue that it is precisely the peaceful coexistence of ancient and medieval literary multicursal models and visual unicursal models that is the key to understanding what medieval people meant by the word laborintus. Analysis of the two paradigms, then, constitutes the substance of Chapter 2. First I examine the formal implications of each model, showing how its characteristic features imply metaphorical potential; for instance, the presence of true and false paths in the multicursal maze may suggest the importance of correct moral or intellectual choice within a confusing world, whereas the single circuitous passage of the unicursal type argues that persistence in the difficult path prescribed by Godor in the devious path designed by the devil, or in the philosopher's complex argument-leads ineluctably to the appropriate destination, be it heaven, hell, or knowledge. Since the single word laborintus denotes both unicursal and multicursal models, and since the name and the visual image of ten appear together, classical and medieval people must have assumed that the paradigms, so contradictory from our point of view, shared enough common features to comprise a single category; therefore I deduce the classical-medieval definition of this category, laborintus, by identif ying the two models' most important shared characteristics. The formal features that both models share broadly outline the general idea or the essence of the labyrinth; they reveal the most important criteria for labyrinthicity and shape the major aspects of the maze's metaphorical potential. Formal features specific to one model or the other fill in the picture and allow considerable flexibility in individual instances: medieval authors can pick the model that best suits the meta- 
phor in mind, or (occasionally) they can select features from both models, or (very rarely) they can describe a transformation of one model into the other.

Chapter 3 shows how three shared formal characteristics generate a taxonomy of labyrinth metaphors: because of certain physical attributes, the labyrinth may be a sign of complex artistry, of impenetrability or inextricability, and of difficult intellectual, epistemological, and verbal process. These categories are illustrated and developed by a wide range of classical and early Christian texts, most of them known in the Middle Ages. ${ }^{7}$ In a general sense, then, Chapter 3 is a case history in how properties of structural models generate, or at least support, literary metaphor; more particularly, the chapter documents the specific metaphorical heritage of the maze on which medieval writers and artists could, and did, draw in creating their own labyrinthine works and metaphors.

Part One thus describes the literary, conceptual, and metaphorical backgrounds of the medieval idea of the labyrinth. Part Two tackles that idea directly. A brief introduction, Chapter 4, considers Latin etymology and vernacular terms for mazes and condenses the various ambiguities of labor intus and domus daedali into three general categories of meaning roughly corresponding to those outlined in Chapter 3: artistry, morality, and difficult process. Each of these categories is then explored. Chapter 5 examines the witness of the medieval visual arts (architecture, gardens, turf and stone mazes, cathedral labyrinths, mazes in manuscripts) to see how it informs written texts by exemplifying, developing, and popularizing certain aspects of the medieval idea of the labyrinth; in return, the literary tradition casts light on some puzzling aspects of visual labyrinths, including the hotly debated function of cathedral mazes. The visual arts are the major medieval locus of the classical and early Christian concept of the labyrinth as magnificent artistry, whether human or divine; they also provide evidence for a purely secular view of labyrinths in a culture that moralized most things, including mazes, and give some insight into the mazes of popular and aristocratic cultures. Thus the interaction of literature and art enhances our understanding of each and enriches our perception of the medieval idea of the labyrinth.

Chapter 5 stresses Daedalian artistry, the visual arts, and the labyrinth in bono; Chapter 6 turns to morality, literature, and the deceitful, nearly

7. In most of this book (Part Three is an exception), I am not concerned with establishing the direct influence of one author on another. Most authors cited would have known both the unicursal visual design and the multicursal literary tradition, and I hypothesize that the idea of the labyrinth and its metaphorical potential are defined theoretically by the structural features, contrasts, and commonalities of the two models. If that is correct, then although many writers probably borrowed labyrinth metaphors from other writers, any writer could visualize a labyrinth and independently deduce appropriate metaphors without the mediating influence of a text. 
inextricable mazes of the world and sin. Most of the texts considered here draw as heavily on the story of the Cretan labyrinth as on the ambiguous building itself, and that narrative context tends to equate the structural windings or errores of the maze with moral error. Three sets of texts are considered. First, several elaborate fourteenth-century mythographical readings of the Cretan legend illustrate the rich and comprehensive metaphorical potential of labyrinthine characters, plot, and structure within the allegorical tradition. Next, fairly casual references to the labyrinth in selected nonmythographical texts document the maze's commonplace metaphorical associations as background for more substantial discussion and fuller appreciation of particularly innovative works. The chapter concludes with four unrelated texts that draw more creatively on the plot and cast of the Cretan legend: the story of Gardinus in the Gesta Romanorum, Boccaccio's Corbaccio, the anonymous Assembly of Ladies, and the Queste del Saint Graal. Each text reflects the medieval idea of the labyrinth and presents the world as a perilous maze in which one learns how to function only with great difficulty, and in each the idea of labyrinth serves as a revealing interpretive tool.

Chapter 7 concludes Part Two with the most interesting group of metaphorical mazes: intellectual and textual labyrinths. Here the maze becomes a model for the complex processes of creating and receiving texts as well as for the object of these activities, the text itself as a work of elaborate art. The chapter addresses the question of a labyrinthine aesthetic and shows how labyrinthine qualities are privileged in literary theory and practice even though the term "labyrinth" is most commonly applied pejoratively to failed art, art that is too complex for its intended audience and purpose.

Part Three, "Labyrinths of Words," consists of four essays in practical criticism. Here I apply concepts developed in Parts One and Two to labyrinthine readings of four interrelated literary texts: Virgil's Aeneid, Boethius's Consolation of Philosophy, Dante's Divine Comedy, and Chaucer's House of Fame. Each of these texts plays with received ideas of the labyrinth, its plot, its characters; and each text reflects not only the idea of the labyrinth in its own age but also labyrinthine aspects of the texts that precede it in this remarkable series. Boethius uses and corrects Virgil's idea of the labyrinth; Dante uses and corrects Virgil and Boethius; and Chaucer makes extraordinarily innovative use of all three masters. These four works constitute a complex study in labyrinthine intertextuality and an appropriate conclusion to my explorations of the idea of the labyrinth. Thus these chapters illuminate the texts they discuss and serve as models for readings of other labyrinthine literature. ${ }^{8}$

8. I intend to pursue some such readings, most notably of several great English Ricardian poems, at a later date. Those who have heard my talks on the labyrinths of Sir Gawain and the Green Knight will have to wait for the appearance of that discussion in print. 
Obviously my methodology is eclectic. By nature and training a literary historian with some interest in modern theory, I share Paul Zumthor's insistence on the need to respect the historicity of a text "and, simultaneously, to redefine, adapt, and sometimes reject modern critical concepts, so as to render them appropriate in seizing this historicity."9 At the same time, I share many medievalists' conviction that a good deal of modern thought has medieval ancestry. ${ }^{10}$ Thus I take a somewhat semiotic approach in considering the labyrinth as a sign with important formal attributes, but I don't see this as ahistorical or anachronistic: medieval philosophers were interested in sign theory and believed that the meaning of any conventional sign (signum ad placitum) derived not only from traditional usage but also from qualities inherent in the sign-its etymology, if the sign is a word; its natural attributes, if the sign is a thing-that make it an appropriate symbol of the thing signified. ${ }^{11}$ Thus, for Isidore of Seville, amicus (friend) is derived from animi custos (guardian of the spirit), and the triangle, its three angles united in one geometrical figure, is an appropriate sign for the Trinity. ${ }^{12}$ Since the labyrinth is both a word and a thing, its etymologies and physical structure help delineate its significance.

Similarly, reader response and reception theories of literature inform my interest in the reception of the labyrinth in the Middle Ages, my speculations on the labyrinth as process, and my assumption that neither the sign's meaning nor its significance in medieval texts is ever strictly determinate. But once again such concerns are not alien to medieval thought: rhetoricians and preachers were acutely sensitive to reader (or listener) response, and the labyrinth topos figures in such ruminations. Augustine discusses the polysemous nature of signs, and the validity of biblical interpretations never intended by the author, as long as these novel interpretations accord with the prevailing code, "the truth taught in other passages of the Holy Scriptures." 13 Ambiguity is as central to medieval hermeneutic practice as it is to the labyrinth itself. Deconstruc-

9. Paul Zumthor, "Comments on H. R. Jauss's Article," NLH, 10 (1978), 367-39o.

1. For example, the labyrinthicity of texts, almost an idée fixe for J. Hillis Miller and a recurrent image in modern critical theory, has considerable medieval precedent, as we shall see. For Miller, see, e.g., "Stevens' Rock and Criticism as Cure, II," Georgia Review, 30 (1976), 330-348, where critical theory and texts are both seen as labyrinths. I hope to publish separately a short study of how medieval labyrinth theory anticipates modern critical theory.

11. On medieval sign theory and related issues, see Ross G. Arthur, Medieval Sign Theory and Sir Gawain and the Green Knight (Toronto: University of Toronto Press, 1987); Marcia L. Colish, The Mirror of Language: A Study in the Medieval Theory of Knowledge (New Haven: Yale University Press, 1968); and Archéologie du signe, ed. Lucie Brind'Amour and Eugene Vance, Papers in Mediaeval Studies, 3 (Toronto: Pontifical Institute of Mediaeval Studies, 1983).

12. Isidore of Seville, Etymologiae 10.4.

13. Augustine, On Christian Doctrine 3.27, trans. D. W. Robertson, Jr. (Indianapolis: Bobbs-Merrill, 1958), p. 102. As far as I know, Augustine does not consider what happens to the stability of a text if any part of it can be destabilized in the manner he describes. On 
tionist ideas are also illuminating: the concept of aporia (the "unpassable path," self-contradiction, paradox) sheds light on the labyrinth's embodiment of paradox, its simultaneous affirmation of antinomies: order/ chaos, imprisonment/liberation, linearity/circularity, clarity/complexity, stability/instability. The view that what one sees in a text, however perverse by traditional critical standards, is worth writing about has encouraged me to be mildly speculative in discussing what a text expresses even if that expression may be remote from the writer's probable intention. But what medieval exegete ever acted differently?

In some ways my discussion of the medieval idea of the labyrinth may even illuminate some contentious issues in contemporary theory. For instance, since the labyrinth is a model simultaneously for artistic intention (the architect's plan), the integrity of a text (the labyrinth as artifact), and the experience of the reader (the well- or ill-informed choices of the maze-treader within the parameters set by the builder), it suggests some possible ways of dealing with the of ten conflicting claims of authorial intention versus reception in critical discourse.

Naturally, this study has limitations. It is not-nor does it aim to be-a catalogue of literary labyrinths comparable to Kern's catalogue of mazes in the visual arts; but I am reasonably sure that I have covered all categories of labyrinthine metaphor as well as a representative selection of classical and medieval works in which the idea of the labyrinth plays a major part. Much as I would have liked to locate certain ways of seeing mazes on the vast map of intellectual history by linking this interpretation with Platonists and that with Aristotelians, say, I have been unable to do so: there seem to be no systematic linkages between labyrinthine metaphors and particular schools of thought, although in a very gradual temporal change the word labyrinth, though not the visual image or the idea, acquired predominately moral and pejorative connotations, as we shall see.

Another unavoidable limitation is suggested by Hans Robert Jauss's comment that "modern scholarship still does not sufficiently differentiate between various levels of reception." 14 For Jauss, high-level reception

reader response approaches to medieval texts, see Chauncey Wood, "Affective Stylistics and the Study of Chaucer," $S A C, 6$ (1984), 21-40, which also discusses the citation from Augustine. Other discussions of modern critical theory in the study of medieval texts include Judson Boyce Allen, "Contemporary Literary Theory and Chaucer," Chaucer Newsletter, 3 (1981), 1-2; Morton W. Bloomfield, "Contemporary Literary Theory and Chaucer," in New Perspectives in Chaucer Criticism, ed. Donald M. Rose (Norman, Okla.: Pilgrim Books, 1981), pp. 23-36; Florence Ridley, “A Response to 'Contemporary Literary Theory and Chaucer,"' ibid., pp. 37-51; and, taking a conservative but constructive stance, A. J. Minnis, Medieval Theory of Authorship: Scholastic Literary Attitudes in the Later Middle Ages (London: Scolar Press, 1984).

14. Hans Robert Jauss, "Theses on the Transition from the Aesthetics of Literary Works to a Theory of Aesthetic Experience," in Interpretation of Narrative, ed. Mario J. Valdés and Owen J. Miller (Toronto: University of Toronto Press, 1976), pp. 137-147. 
is the "dialogue of great authors," which creates truly innovative (and quite unpredictable) readings-Pascal reading Montaigne, for instance. Part Three of this book grapples with high-level readings in the labyrinthine tradition and by its very nature is not susceptible to "proof," if proof is ever possible in literary criticism. We know how commentators like Servius and pseudo-Bernard Silvester read the Aeneid, and we know how Benvenuto da Imola and Guido of Pisa read Dante's reading of the Aeneid in the Divine Comedy, but neither kind of evidence tells us how Dante read Virgil and his labyrinths. Middle-level reception involves "institutionalized reading," interpretations of texts and visual images by skilled readers whose comments reflect competence but not the idiosyncrasies of genius and result in "traditionalized and authorized meaning." Much of the material presented in Chapters 3 through 7 reflects middle-level reception and development of the idea of the labyrinth: commentaries on and uses of real and metaphorical labyrinths by men literate in Latin, schooled in the trivium (grammar, rhetoric, and dialectic), familiar with such standard curriculum authors as Virgil and Ovid and their commentators, and trained to read and interpret in predictable ways. Here I have drawn on as many kinds of primary written and visual sources as possible: letters, commentaries, poetry, historical and geographical treatises, theology, biblical exegesis, encyclopedias, arts of preaching and rhetoric, sermons, formularies, philosophical works, manuscript illuminations, and so on-material that defined and transmitted of ficial institutional culture. The idea of the labyrinth that evolves in the first two parts of this book, then, is primarily the idea shaped and accepted in middle-level readings, for this is the idea that can most easily be reconstructed and documented. At the lowest level is "pre-reflective" reading, the personal responses of a relatively inexperienced reader encountering a work for the first time. There is little classical or medieval evidence for low-level reading of the maze for the simple reason that the medieval equivalents of modern low-level "readers" were illiterate and their responses to the labyrinth went unrecorded. We may detect traces of low-level readings in the names of turf-mazes or labyrinthine stone circles, or in preaching manuals and sermon collections whose content might have been transmitted to unlettered parishioners. But what is transmitted is not necessarily what is received, so we can only guess at low-level reception of the labyrinth in the Middle Ages. Thus much of this book recreates a middle-level horizon of expectations regarding labyrinths, and its conclusions about the medieval idea of the labyrinth are neither comprehensive nor a handy interpretive template to be applied mechanically to all medieval uses of the image.

There is yet another limitation to be acknowledged. I began studying medieval labyrinths almost twenty years ago while lecturing on Chaucer's House of Fame as a labyrinthine poem, and though I have worked on the 
topic ever since, I have certainly not read everything published or in manuscript that might be relevant. Moreover, I am not a classicist or a specialist in Italian and French literature, and I have not read all the secondary material on the Aeneid or the Divine Comedy or the Queste del Saint Graal, to name but three works I treat at some length. Rather than ref rain from discussing obviously pertinent texts, I have forged ahead in the hope that by looking at old material with fresh eyes, much-appreciated guidance from willing experts, and a different perspective-the view from the labyrinth-I can suggest new threads to follow through these textual mazes. I acknowledge these problems with regret but also with a lively awareness that treaders of multicursal labyrinths inevitably leave some paths untraced and forget what they learned in others. I sometimes think it is a miracle that I have extricated myself from this endless labyrinth of contraries at all: nineteenth-century discussions of church mazes are dotted with references to one M. Bonnin, who had collected more than two hundred maze designs that he intended to publish as soon as he had completed the accompanying text. ${ }^{15}$ So far as I can tell, nothing ever appeared in print, and the cautionary figure of $\mathrm{M}$. Bonnin stalks my nightmares.

Before this errand into the maze begins in earnest, two small points: first, in dealing with some examples of labyrinth metaphors, I address meanings that emerge from the immediate context of the image rather than from its place in the whole work, lest a long study grow completely out of bounds. Second, since I want this book to be useful not only to medievalists but also to nonspecialists interested in labyrinths, I quote most texts in translation, either a published version or my own. ${ }^{16}$

Finally, for readers who may not have details of the Cretan legend at their fingertips, I provide a summary based on Ovid but including a few details and variants from other classical and medieval retellings.

\section{- The Cretan Labyrinth Myth •}

Outraged by the death of his son Androgeos in Athens, King Minos of Crete besieged that Greek city. Meanwhile, his wayward wife Pasiphae fell passionately in love with a handsome bull. To satisfy her lust, she enlisted the help of the Athenian Daedalus, master inventor of antiquity,

15. See Matthews, p. 201.

16. I have crosschecked published translations against the original and usually cite both versions-or easily available, facing-page Loeb editions-in notes. For my own translations, I have had generous assistance from Brian Stock and A. G. Rigg (Latin), Ross G. Arthur (Greek), and Christina Hawkes (German). When shades of meaning in the original language are important, I include the original in brackets. 
who built her a wooden cow covered with hides. Pasiphae climbed into the cow, mated with the bull, and conceived the Minotaur, a monster with the body of a man and the head of a bull. When Minos returned triumphantly to Crete, he was shamed by this visible proof of his wife's lechery, and he bade Daedalus construct the confusing and inextricable labyrinth in which to emprison and conceal the Minotaur. So bewildering were the maze's paths that even Daedalus could scarcely find his way back to the entrance.

Every nine years (or, some say, every year), Minos fed the Minotaur with Athenian youths sent as tribute in atonement for the death of Androgeos. At the time of the third tribute, one of the fatal lots fell to Theseus, King Aegeus's son, who, with his companions, was brought to Crete. But Ariadne, Minos's daughter, fell in love with the young prince and determined to save him from labyrinth and Minotaur alike. To this end-and, some say, on the advice of the crafty Daedalus-she gave Theseus a clue of thread, which he tied to the entrance of the labyrinth and unwound as he followed the twisting paths to the center. There, some say, he took Ariadne's second gift, a ball of pitch, and threw it into the Minotaur's gaping mouth. Choking on the ball and unable to attack the man who should have been his prey, the Minotaur fell victim to Theseus's sword (or, in other accounts, his club). The young Athenian rewound the clue of thread, retraced his steps, and emerged saf ely from the hitherto inextricable labyrinth. Taking Ariadne and her young sister Phaedra with him, Theseus set sail for Naxos, where he abandoned Ariadne. Moved by her plight, the god Dionysus consoled her, transforming her crown into a constellation. Theseus and his companions sailed on to Delos, where they performed a labyrinthine dance in celebration of their escape from Crete. But Theseus's triumphant homecoming to Athens turned to tragedy. He had promised his father Aegeus that if by some miracle he escaped the labyrinth, he would replace the black sails on his ship with white ones. Having already forgotten Ariadne, Theseus was equally forgetful of his promise to his father: the black sails remained aloft, and the distraught Aegeus hurled himself into the sea.

Meanwhile Daedalus, inventor of the labyrinth, was himself made prisoner. Some say that Minos cast him and his son Icarus into the labyrinth as punishment for assisting Pasiphae or for having helped Ariadne save Theseus; others claim that Minos refused to let so ingenious an inventor return home to Athens. Whatever the truth may be, Daedalus made wings so he and Icarus might escape the maze by flight. Daedalus warned his son to take a middle course - the sun would melt the wax that held the feathers in place, the waves would drench them. But Icarus ignored his father's advice, soared sunward, and plummeted into the sea.

As Daedalus mourned, he was taunted by a partridge who had once 
been his own nephew, Talos (or Perdix). This precocious lad had been apprenticed to his uncle, but when the child proved his brilliance by inventing the saw and the compass at the tender age of twelve, Daedalus grew jealous, threw him off the Acropolis, and fled to Crete. Athena, pitying the child, turned him into a partridge, a bird that still shuns heights because it remembers Talos's terrible fall.

After the death of Icarus, Daedalus flew to Italian Cumae, where he built a temple to Apollo, sculpting on its doors the story of the Cretan labyrinth. Some say that Daedalus then flew to Sicily, where he was welcomed by King Cocalus. Still seeking vengeance, Minos offered a reward to anyone who could thread a tightly spiraled shell. Daedalus, as crafty as ever, drilled a tiny hole in one end, inserted an ant with a thread attached to its body, induced it to enter by smearing honey on the shell's mouth, and thus traced the windings of the shell. Sure that no one but Daedalus could have accomplished such a task, Minos came to claim him, but the Sicilians, reluctant to give Daedalus up, murdered Minos. 
